\title{
QUALIFICAÇÃO E ORGANIZAÇÃO FLEXÍVEL DO TRABALHO: ELEMENTOS PARA UM OLHAR CRÍTICO
}

\author{
Qualification and flexible work organization: \\ elements for a critical view
}

Geraldo Augusto Pinto*

\section{Resumo}

O objetivo deste artigo é apresentar um conjunto de proposições críticas acerca das novas exigências de qualificação mediante 0 avanço da automação microeletrônica e dos sistemas de organização flexível do trabalho. Para isso, é feita uma revisão da literatura, em especial da Sociologia, da Economia e da Educação, por meio da qual são analisados aspectos da passagem do sistema de organização taylorista/fordista para o sistema toyotista, no que tange às exigências de escolaridade, de formação profissional e de perfil comportamental dos trabalhadores. Os resultados mostram que, embora haja elementos positivos, como a ampliação da autonomia dos agentes nos locais de trabalho e a necessária elevação da escolaridade, há, contudo, saldos negativos, como a emergência do desemprego estrutural e da informalidade, seguidos por uma intensificação de atividades e responsabilidades aos trabalhadores mantidos empregados, o que recoloca em novos patamares de reflexão, um conflito histórico entre as classes sociais no capitalismo.

Palavras-chave: Sociologia do trabalho. Inovação tecnológica e mudança organizacional. Qualificação do trabalho. Formação profissional. Formação educacional.

* Mestrado e doutorado em Sociologia, pela Universidade Estadual de Campinas. Email: geraldoaugusto@hotmail.com 


\section{Abstract}

The purpose of this article is to present a set of critical propositions about the new qualification demands through microelectronics and flexible work organization systems. In order to achieve this, a literature review was conducted in the area of Sociology in special, Economy and Education. It was analysed the transition from the taylorist/fordist organizational system to the toyotist, concerning professional educational demands and behavioral profile of workers. The results showed that, although there are positive elements, like autonomy growth of agents in workplaces and required educational improvements, there are negative effects, such as the rising of structural unemployment and informality followed by an increase in activities and responsibilities towards employees, reshaping reflections over a historical conflict between classes in capitalism.

Keywords: Sociology of work. Technological innovation and organizational change. Work qualification. Professional formation. Educational formation.

\section{INTRODUÇÃO}

Um conjunto de transformações sociais, econômicas e políticas caracteriza 0 que atualmente se denomina como processo de "reestruturação produtiva". Trata-se de um movimento amplo, cujo avanço ocorre em duas frentes complementares. De um lado, está em curso uma obsolescência do sistema taylorista/fordista de organização do trabalho e de relações entre empresas ao longo das cadeias produtivas, face ao avanço dos sistemas de organização flexíveis, como o toyotista (apontado pela literatura como um dos mais importantes $)^{1}$. De outro lado, há um impasse entre o recuo de uma ação estatal protetora de reservas de mercado a empresas nacionais, bem como abrangente em termos de compensações sociais à classe trabalhadora em face do avanço das políticas neoliberais, às quais se atribui a renúncia a estas medidas protecionistas ${ }^{2}$.

Estas frentes de mudanças tomaram corpo nos países capitalistas centrais, em maior ou menor grau, a partir do contexto de instabilidade 
da década de $70^{3}$, tendo, desde então, avançado em direção à periferia do sistema.

Dentro desta perspectiva, o objetivo deste artigo é contribuir para um debate acerca da expansão desta reestruturação produtiva, especialmente no que tange aos impactos que as novas formas de automação e de organização flexível do trabalho têm tido sobre os perfis de qualificação profissional, educacional e comportamental dos trabalhadores.

Para isso, faremos um balanço bibliográfico pelo qual buscaremos expor, numa perspectiva crítica, as principais características destes perfis de qualificação inerentes ao sistema taylorista/fordista e ao seu sucessor, o sistema toyotista, indagando-se acerca das conseqüências destas mudanças sobre os trabalhadores.

\section{INOVAÇÕES TECNOLÓGICO-ORGANIZACIONAIS E QUALIFICAÇÃO DO TRABALHO}

Partiremos aqui do pressuposto de que o objetivo da produção capitalista é a acumulação de capital. Tal objetivo é mantido através da concorrência entre os empresários (detentores dos meios de produção e compradores de força de trabalho), sobre as possibilidades de ampliação dos lucros: (1) seja pelo rebaixamento dos salários ou extensão das jornadas de trabalho - através da mais-valia absoluta; (2) seja por métodos que elevem a produtividade pela redução crescente do tempo de trabalho necessário à produção de mercadorias e serviços - através da mais-valia relativa; (3) seja pelo aumento do giro de capital através da taxa decrescente do valor de uso das mercadorias e serviços produzidos ${ }^{4}$.

Nós nos concentraremos na extração de mais-valia relativa, pois é exatamente este o âmbito que engloba as estratégias de ampliação da produtividade por meio da combinação entre formas de automação ${ }^{5}$ e de organização do trabalho. Trata-se, assim, de um processo que designaremos como "inovações tecnológico-organizacionais", e por meio do qual traçaremos um debate acerca da questão da qualificação do trabalho.

A qualificação do trabalho é um tema polêmico. Primeiramente, por envolver pontos de vista e significações contraditórias, quando analisada sob a ótica de uma sociedade de classes; em segundo lugar, pela própria 
ausência de métodos que, a partir de critérios comuns, permitam ser avaliados os diferentes graus deste atributo do trabalho em circunstâncias diversas. Definiremos, portanto, a expressão “qualificação do trabalho", no contexto da produção capitalista, segundo Bruno (1996, p. 92):

Nesta perspectiva, a qualificação diz respeito à capacidade de realização das tarefas requeridas pela tecnologia capitalista. Esta capacidade pressupõe a existência de dois componentes básicos: um muscular e outro intelectual, que têm sido combinados de diferentes formas nas sucessivas fases do capitalismo e nos diversos tipos de processo de trabalho. Neste sentido, diria que é qualificada aquela força de trabalho capaz de realizar as tarefas decorrentes de determinado patamar tecnológico e de uma forma de organização do processo de trabalho. Isto já confere ao termo temporalidade e relativiza seu conteúdo, à medida que em cada estágio de desenvolvimento social e tecnológico e em cada forma de organização do trabalho novos atributos são agregados à qualificação e novas hierarquizações são estabelecidas entre eles.

Tomando-se a evolução histórica do capitalismo, em linhas gerais pode-se caracterizar o desenvolvimento das qualificações dos trabalhadores numa sucessão de etapas que se inicia com a capacidade de realizar operações que, inicialmente, exigiam grande esforço físico e habilidades manuais específicas, para, num momento posterior, atingir novos patamares, em que, ao lado do crescente aprimoramento manual e muscular, foram sendo desenvolvidos componentes intelectuais cada vez mais complexos, os quais hoje se tornaram atributos predominantes (BRUNO, 1996).

Não obstante este ter sido um longo - e certamente não linear processo histórico, tal deslocamento do foco da exploração da capacidade de trabalho pelo capital, passando do componente muscular ao intelectual, constituiu, no século XX, um dos elementos fundamentais na reestruturação dos processos e atividades de trabalho, levando à obsolescência do sistema taylorista/fordista rumo aos sistemas de organização flexíveis do trabalho, 
como o toyotista ${ }^{6}$. Neste sentido, tal deslocamento avançou mediante as possibilidades abertas pelo desenvolvimento das forças produtivas e sociais deste período, particularmente após a II Guerra Mundial.

Assim, há que se considerar, por um lado, o grau - maior ou menor, conforme as circunstâncias históricas de cada país - de proteção do seu conhecimento (prático e teórico), que a classe trabalhadora logrou obter contra os avanços das estratégias de desqualificação capitalistas e, nesta mesma luta, o aumento das qualificações genéricas apresentado pelas sucessivas gerações de trabalhadores. Isso ficou visível no desenrolar das lutas sociais nas décadas de 60 e 70 , organizadas por amplos setores do proletariado mundial, independentemente das burocracias sindicais e partidárias e tendo como uma de suas metas avançar na direção de uma reorganização dos processos de trabalho em moldes novos e antagônicos aos propostos pelo sistema capitalista (BRUNO, 1996).

Por outro lado, é evidente que tais fatos chamaram a atenção do empresariado para a capacidade que a classe trabalhadora possuía de não apenas mobilizar-se politicamente, mas de refletir crítica e tecnicamente acerca de sua atuação nos processos de trabalho em que estava inserida. Ou seja, o taylorismo/fordismo não lograra exterminar a acumulação de um conhecimento tácito sobre o trabalho pelos trabalhadores, advindo da relação direta entre objeto e sujeito do trabalho, nem mesmo nos níveis em que a divisão entre "concepção" e "execução" havia sido levada ao extremo. $\mathrm{O}$ avanço da ciência e suas inovações aplicadas aos processos de trabalho, como a automação microeletrônica e a tecnologia da informática, vieram, por sua vez, permitir a exploração de atividades cada vez mais complexas, atuando não somente como novas forças produtivas, mas também como novos instrumentos de controle do capital sobre o trabalho.

Depreende-se destes movimentos que os perfis de formação profissional, de escolaridade e mesmo de comportamento, exigidos dos trabalhadores em cada caso particular e num dado momento histórico, são constantemente questionados, por eles mesmos e pelo empresariado, no contexto da concorrência capitalista, quando da emergência das inovações tecnológico-organizacionais. Ao mesmo tempo, as qualificações dos trabalhadores, compreendidas como competências e habilidades manuais 
e intelectuais, adquiridas e aplicadas aos diferentes processos de trabalho, sobre uma base educacional e profissional, são, por sua vez, fatores também determinantes do desenvolvimento e da aplicação destas inovações tecnológico-organizacionais.

Trata-se, portanto, de um processo que evolui mediante uma reciprocidade dialética entre as formas de sociabilidade - a luta entre classes sociais distintas - e o desenvolvimento da ciência e sua aplicabilidade. Sendo assim, vejamos como estas relações entre a organização do trabalho e a automação, implicaram em mudanças nas formas de gestão da força de trabalho e nos perfis de qualificação dos trabalhadores ao longo do século $\mathrm{XX}$, tendo por base o sistema taylorista/fordista e o sistema toyotista.

2.1 Organização flexível e qualificação do trabalho

No sistema taylorista/fordista, dada a parcelização e simplificação a que foi submetida a intervenção do trabalho humano, chegou-se ao ponto em que a idade, a experiência, a habilidade, o conhecimento e a própria "iniciativa" (um obstáculo a ser contornado, na visão de Taylor) dos trabalhadores não constituíam impedimentos para que fossem demitidos e substituídos por outros, indefinidamente, sem que isso afetasse diretamente a continuidade e até mesmo a qualidade do trabalho. Por isso, dois elementos desde sempre acompanharam este sistema: os altos níveis de absenteísmo e, conseqüentemente, de rotatividade nos quadros das empresas, especialmente (mas não somente) os mais próximos às esferas operacionais. Aliás, junto a isso, desde sempre também esteve associado um baixo nível de qualificação educacional e profissional dos trabalhadores, naturalmente devido ao desinteresse pelo aprendizado no trabalho, que, nestas condições, nada mais é do que a negação de um processo de aprendizado.

O grau em que a substituição dos trabalhadores neste sistema atingiu, junto ao baixíssimo tempo de treinamento e nível de complexidade exigidos nas atividades, pode ser ilustrado com números da própria Ford Motor Company, surpreendentemente expostos por Henry Ford como uma dádiva gloriosa de seu sistema de organização:

Uns 43\% de todos os serviços não requerem mais do que um dia de aprendizagem; 36\% requerem de um até oito dias; 
6\%, de uma a duas semanas; 14\%, de um mês a um ano; 1\%, de um a seis anos. [...] Os trabalhos mais fáceis foram por sua vez classificados, para verificar quais deles exigia o uso completo das faculdades; comprovou-se então que 670 trabalhos podiam ser confiados a homens sem ambas as pernas; 237 requeriam o uso de uma só perna; em dois casos podia-se prescindir dos dois braços; em 715 casos de um braço, e em 10 casos a operação podia ser feita por um cego (BRAVERMAN, 1977, p. 145-148, apud FLEURY; VARGAS, 1983, p. 25).

O sistema toyotista, desenvolvido por Taiichi Ohno, na Toyota Motor Company, em condições históricas particulares do Japão após os anos 50, voltou-se a uma organização do trabalho caracterizada por uma progressiva “desespecialização” (CORIAT, 1994), da qual adveio, nas palavras de Abreu et al. (2000, p. 56-57), uma "expansão dos deveres e responsabilidades atribuídos aos trabalhadores na linha de produção”.

Por expansão das "responsabilidades" deve-se entender a fusão de distintas funções já existentes e até então tradicionalmente separadas pelo taylorismo/fordismo em departamentos distintos, como, por exemplo, a função de manutenção do aparato produtivo, a de controle de qualidade e a de transformação propriamente dita dos insumos em produtos. Cada uma destas funções limitava-se a diferentes grupos de atividades, rotineiramente realizadas por vários trabalhadores. Sendo fundidas num só posto de trabalho, este adquiriu então o caráter de uma "multifuncionalidade", pois que se aglutinaram nele todos os "deveres" ou, mais objetivamente, as atividades inerentes a estas funções, exigindo-se, portanto, do trabalhador aí empregado, a responsabilidade por sua execução dentro da mesma jornada. Denomina-se, portanto, a quem executa tais funções e atividades, um trabalhador "polivalente" ou "multifuncional".

Esta nova organização passou a exigir dos trabalhadores novas qualificações profissionais, educacionais e mesmo comportamentais, as quais abrangem, por um lado, a maior experiência no exercício da função (o "conhecimento tácito"), e, por outro, capacidade em inovar no âmbito das atividades desempenhadas, de adaptar-se às variações dos objetivos 
e das tecnologias utilizadas (capacidade de "aprender a aprender"), de tomar decisões e prevenir desajustes operacionais, de selecionar e relacionar informações, de desenvolver conhecimento por simbolização, além das tradicionais habilidades manuais, que permitam o uso eficiente de equipamentos e instrumentos de trabalho de alta precisão técnica (BRUNO, 1996; JACOBI, 1996).

Tais perfis de qualificação, entretanto, não foram generalizados a todos os trabalhadores. Em sua maioria, têm sido encontrados nas grandes empresas líderes, na maior parte dos casos (dependendo do porte da empresa e do segmento em que atua) nos círculos produtivos e administrativos mais importantes, concentrando-se, ademais, nos países capitalistas centrais, tais como Japão, ou em lugares (como na "Terceira Itália”, ou na Suécia, região de Kalmar) em que se tem força de trabalho de alto nível de formação, tanto técnica quanto escolar, garantias de emprego com baixos níveis de rotatividade, pequenas diferenciações salariais, contratações coletivas efetivas e negociação sindical quanto a processo de trabalho e inovação (CASTRO, 1995; MATTOSO, 1994).

Por outro lado, diversos estudos ${ }^{7}$ têm observado uma tendência das empresas, ao implantarem a organização flexível, de "enxugar" seus quadros, mantendo-se um número mínimo de trabalhadores em atividades cujo exercício envolve a ampliação de responsabilidades, do que tem decorrido um aumento significativo da intensidade do trabalho, seguida de uma elevação do controle gerencial.

O sistema toyotista ainda promoveu uma redução substancial das estruturas hierárquicas das plantas, diminuindo o número de chefias e possibilitando uma maior autonomia por parte dos trabalhadores na condução dos processos produtivos. Em experimentos ao longo de trinta anos, a Toyota passou a organizar as seções internas de suas fábricas e escritórios na forma de "equipes de trabalho", as quais se relacionam entre si usando a simbologia de clientes e fornecedoras de produtos e serviços, aplicada às empresas no âmbito das cadeias produtivas (PINTO, 2007a, 2007b).

Percebe-se que todas estas reformulações, se tomadas do ponto de vista dos objetivos do taylorismo/fordismo, condicionaram bastante o êxito 
dos resultados à motivação dos trabalhadores pelas metas de competitividade, pelos programas de qualidade e pelas novas rotinas implementadas. E, de fato, tais mudanças fizeram emergir formas de "participação" destes trabalhadores, visando "envolvê-los" através da difusão de informações sobre o desempenho da empresa e, assim, "motivá-los", seja premiandoos por idéias através de planos de sugestões, seja pela participação nos resultados (ABREU et al., 2000; LIMA, 2004).

Sobreveio, então, uma demanda por trabalhadores não apenas tecnicamente mais qualificados e dotados de habilidades específicas, mas também de maior flexibilidade operacional e desenvoltura pessoal em matéria de liderança, atuação em equipe, cooperação e assunção de riscos, agilidade de resposta, iniciativa e envolvimento com os objetivos empresariais; capacidade de conceituar sobre suas atividades de trabalho, estabelecer referências e proposições de ação comum entre funções distintas e com diferentes graus de complexidade; inventividade, adaptabilidade a mudanças, busca de atualização permanente e tendência à melhoria contínua nos resultados, além de certa autonomia na resolução de problemas cotidianos, através da assimilação de normas disciplinares e comportamentais (BRUNO, 1996; LEITE, 1995; RIQUELME, 1994; SALM, 1998).

A organização do "trabalho em equipe", no entanto, ao tempo em que resgata o espírito de coletividade no trabalho, quebrando o isolamento do taylorismo/fordismo, por outro lado estimula a competição entre os membros destas equipes, tanto interna quanto externamente, instalando cobranças pelo cumprimento de metas colocadas pelas gerências. Isso decorre da combinação entre uma descentralização de responsabilidades entre os trabalhadores, pari passu a um sistema de avaliação dos seus desempenhos individuais que se localiza fora e acima das equipes das quais participam. Segundo Shiroma (1993, p. 66):

a gerência japonesa usa o grupo como instrumento de controle, baseando-se na forte competição individual entre os trabalhadores para quebrar os meios coletivos de resistência. A pressão sobre o indivíduo, mediada pelo grupo, faz com 
que este sistema funcione. Se um membro está ausente, os outros aumentam sua carga de trabalho para cobrir a falta do colega.

Ao passo em que crescem as tensões em sentido "horizontal" (entre os próprios trabalhadores), as tensões "verticais" (entre gerência e trabalhadores) buscam ser amenizadas por estratégias como equiparação entre trabalhadores em termos de salários ou benefícios. Caminha-se, assim, para uma atenuação do controle direto e hierárquico, paralelamente ao desenvolvimento de uma autodisciplina pessoal. Posto que se aproveita neste processo o confronto em prol de seu potencial criativo para a acumulação de capital, a organização das equipes constituiu-se, para além de um mecanismo de controle, também um meio de intensificação dos ritmos e volume do trabalho (SHIROMA, 1993).

PesquisascompiladasporAraújo, CartonieJusto(2001)demonstraram estar em curso estas transformações em empresas de autopeças, de máquinas-ferramenta, de aparelhos domésticos e de computadores, na região de Campinas-SP, revelando que o aumento da responsabilização dos empregados pela qualidade e seu envolvimento com metas de produção ou vendas levaram a uma competição tão extrema, que a intensificação do ritmo e a extensão das jornadas a que se submeteram têm gerado aumentos significativamente maiores nas doenças ocupacionais ao longo dos anos 90, com destaque para as Lesões por Esforços Repetitivos (LER).

Por outro lado, se atentarmos para as relações entre as empresas nas cadeias produtivas, estes mesmos estudos realizados na região de Campinas demonstraram que houve também, durante a década de 90, um avanço significativo da terceirização, com crescente precarização das condições de trabalho nas empresas terceiras, as quais, além de jornadas flexíveis e contratos de trabalho informais e instáveis, vêm pagando salários menores que o piso das categorias a que pertencem, oferecendo, ainda, condições inseguras de trabalho.

Ademais, a mesma pesquisa também diz que tal diferenciação se expressa na qualificação do trabalho em cada caso, de modo que: no núcleo de $1^{\circ}$ nível das cadeias produtivas, as grandes empresas transnacionais vêm transferindo aos trabalhadores maiores responsabilidades na condução 
do processo produtivo, buscando, ademais, seu maior envolvimento e participação - ao passo que nos círculos mais "externos" destas cadeias, as pequenas e médias empresas, geralmente nacionais, têm intensificado significativamente os ritmos de trabalho, aumentando o desemprego e precarizando as condições de trabalho e de saúde dos funcionários.

Estudos como os de Antunes (1998) e Ruas (1994) vão além e apontam que tais aspectos são verificáveis em nível nacional, estando, aliás, a desregulamentação e a organização flexível do trabalho, ainda mescladas a elementos do taylorismo/fordismo em muitos setores, o que caracteriza um avanço peculiar da reestruturação produtiva no Brasil, pelo qual a baixa remuneração da classe trabalhadora, ao invés de constituir um obstáculo ao máximo aproveitamento das inovações tecnológico-organizacionais (pela via da cooperação e do envolvimento), permanece como mais um elemento de competitividade e, portanto, de atração do capital externo produtivo ao país.

Por fim, mesmo nas empresas transnacionais mais desenvolvidas e situadas nos vértices das cadeias produtivas, o aumento de deveres e responsabilidades, bem como os maiores níveis de escolaridade exigidos aos trabalhadores já empregados ou candidatos a vagas, não resultaram em elevações salariais ou benefícios equivalentes (PINTO, 2007b). Além de não haver uma legislação trabalhista específica ao assunto, estando estas inovações tecnológico-organizacionais sendo negociadas nos acordos e convenções coletivas, segundo Abreu et al. (2000), as pressões por redução de custos e o desemprego generalizado têm facilitado às empresas no Brasil a frear os salários e a concessão de benefícios frente à aceleração da produtividade do trabalho.

Lancemos, agora, um olhar sobre a questão da automação.

\section{Automação e qualificação do trabalho}

Incorporando a racionalização e o automatismo, inerentes à metodologia de Taylor, e expandindo-os ao máximo, Ford mecanizou o maior número possível de atividades de trabalho, tanto que com isso logrou estabelecer uma cadência quase constante entre todos os processos produtivos nas plantas de sua empresa, sob a qual o ritmo da entrada das matérias- 
primas pelos portões de trás era praticamente acompanhado pelo da saída dos automóveis prontos pelas portas da frente das fábricas.

Essa cadência constante no consumo das mercadorias na produção não apenas se manteve, como foi aprimorada pelos sistemas flexíveis de organização, como o desenvolvido por Ohno, na Toyota. Mas a metodologia de organização do toyotismo foi redirecionada à desespecialização, a qual, visando à multifuncionalidade, fez que se estabelecesse um uso mais intensivo e menos rotativo da força de trabalho, cujas exigências de qualificação, como experiência, habilidades, conhecimentos gerais e específicos e, inclusive, a própria "iniciativa”, o comprometimento e o desempenho individual, passaram a ser os principais alvos das administrações de recursos humanos.

A partir de então, as empresas passaram a buscar o que se poderia designar como uma "flexibilidade interna" na alocação de um número mínimo de trabalhadores, conforme a situação exigisse. E devido a isso o sistema toyotista não se fundamentou, essencialmente, em seus primeiros passos, num desenvolvimento puro e simples da maquinaria; mas, sobretudo, numa reorganização espacial dos processos de trabalho e numa reformulação das responsabilidades e deveres inerentes a cada agente neles envolvidos.

Esta constatação não deve obscurecer, entretanto, o fato de que a flexibilidade interna atingida pelo sistema toyotista possibilita - e muitas vezes requer - processos de automação crescentes, como se pode constatar por uma de suas técnicas principais, a "autonomação", que consiste no uso de dispositivos de controle nas máquinas que lhes permitam operar sem a intervenção humana direta, produzindo quantidades exatas e parando automaticamente no caso de produção defeituosa (CORIAT, 1994).

A automação, em especial a de base microeletrônica, atinge radicalmente os conhecimentos teóricos e práticos relativos aos processos de trabalho, à medida que computadores passam a monitorar, a checar e mesmo a se reprogramar em caso de erro. Por conseguinte, a distribuição do conjunto de conhecimentos entre as forças produtivas humanas e materiais tem sido alterado, culminando na incorporação, 
pelas máquinas, de atividades até então exclusivamente humanas, como a armazenagem de informação, cálculos, desenhos e raciocínio lógico, tangendo, assim, a própria esfera da concepção ou do "projeto mental" do trabalho (CASTILLO, 1996).

A implantação destes dispositivos altera, assim, a relação dos trabalhadores com a condução dos processos de trabalho, gerando, entre outras conseqüências, o fato de que agora, em grande parte das atividades automatizadas, quase não se "executa" propriamente, mas se "interpretam" as informações geradas pelas máquinas e se "vigia” o funcionamento integral do sistema e seu estado (RIQUELME, 1994). $E$, nesta intervenção, as máquinas vêm modificando os ambientes de trabalho e as relações entre os seus agentes, pois, ao interporem um novo conjunto de informações simbólicas entre os trabalhadores e seus processos de trabalho, geram uma nova forma de relacionamento entre ambos (CASTILLO, 1996).

Partindo de um ponto de vista histórico ainda mais amplo, se podemos afirmar que a transferência das ferramentas das mãos dos trabalhadores às máquinas significou um avanço da "objetivação", nestas máquinas-ferramenta, do conhecimento acumulado pelos trabalhadores acerca da execução dos vários tipos de atividades, o crescente nível de autoregulação desses aparelhos, permitindo-lhes operarem sendo apenas programados e supervisionados por um seleto grupo de trabalhadores, tem promovido um aumento ainda maior da disparidade na repartição entre os conhecimentos concentrados nas máquinas e nos homens e o seu papel na divisão do trabalho social (CASTILLO, 1996).

O resultado deste processo tem levado a uma intensa desvalorização de um conjunto de conhecimentos historicamente acumulados pela classe trabalhadora, tornando-os obsoletos e, por conseguinte, desnecessários os seus possuidores. Se os trabalhadores não podem ser absolutamente excluídos do sistema de produção de mercadorias, é certo que a tendência de aumento das máquinas em relação ao volume de trabalho humano que as opera representa, além da redução do tempo de trabalho socialmente necessário, a redução dos custos que as forças produtivas humanas requerem ao capital no contrato de sua "venda" (CASTILLO, 1996). 
Esta redução de custos ocorre não somente pela dispensa dos encargos sociais, mas pelo aprimoramento do controle exercido sobre os trabalhadores através do desemprego estrutural, pois o fechamento de postos de trabalho e a formação de um crescente "exército industrial de reserva" ${ }^{8}$ reduz o poder de barganha do valor dos salários, negociados pela classe trabalhadora com os empregadores. E esta situação permite obrigar os trabalhadores a se responsabilizar pela permanente capacidade de adaptação à operação de novas, mais complexas e cada vez mais caras instalações.

Os resultados desse movimento mais amplo são negativos para todas as classes sociais. A formação educacional e profissional dos trabalhadores constitui uma parcela de toda a produção social, que é reinvestida na própria reprodução da força de trabalho, processo no qual são necessários cursos, treinamentos, equipamentos e mesmo o emprego de outros trabalhadores. $\grave{A}$ medida que os atributos da qualificação da força de trabalho estão sujeitos à compra e à venda no capitalismo, um trabalhador desempregado é um trabalhador que não consegue vender - realizar o valor - de sua qualificação, e uma qualificação não reconhecida socialmente torna-se desperdício de uma porção do trabalho social investido em formação de capacidades particulares de trabalho, de modo que, no cômputo geral, o desemprego eleva significativamente os custos de formação de cada trabalhador ocupado (CASTILLO, 1996).

Há, por fim, um outro aspecto a ser analisado. Se ao longo das várias etapas do capitalismo tem havido, ligada à automação, uma obsolescência das qualificações acumuladas pela classe trabalhadora, no estágio atual de emergência dos sistemas de organização flexíveis, como o toyotista, a automação tem se mostrado não somente mais intensa, como também mais complexa e custosa. Sendo assim, os altos custos da compra dos equipamentos e o tempo decorrente de suas adaptações à experiência dos trabalhadores torna necessária uma rápida aquisição, por parte destes, de um conjunto de conhecimentos que lhes possibilite extrair o máximo de rentabilidade das máquinas, em função do seu tempo de uso total, considerando-se o tempo de amortização que essas imensas quantias de capital concentradas nas máquinas requerem, antes que elas próprias se tornem, também, obsoletas. 
A força de trabalho assume, então, um papel estratégico, enquanto assegura o correto funcionamento da maquinaria, mediante atividades de prevenção, diagnóstico e reparação eficiente de falhas. Isso faz com que o sistema se encontre ameaçado por erros humanos, pelo desvio de interesses decorrentes da relação de assalariamento, bem como pela própria vida social nas oficinas e escritórios, caracterizada por tolerâncias, arranjos e compromissos que colocam em questão a racionalidade fria das máquinas.

Em vista disso, a preocupação das empresas, ao investir em automação, é sobretudo planejar uma restrição da intervenção dos trabalhadores, predeterminando as operações a serem por eles realizadas, o que resulta numa tendência a conceber uma organização do trabalho que, ao invés de ampliar, limita aos trabalhadores uma compreensão acerca do que os projetistas das instalações automatizadas consideram como necessária e suficiente. Ademais, à medida que se busca reduzir ao máximo e rapidamente o número de trabalhadores necessários, tais projetos também se esforçam para automatizar a maior parcela possível do controle supervisório dos processos (introduzindo alarmes e paradas automáticas diante da ocorrência de defeitos e incidentes), a fim de que se possa liberar a força de trabalho da obrigação de observar o funcionamento das instalações e alocá-la em outras tarefas, muitas vezes ainda mais anexas ou periféricas (FREYSSENET, 1993).

A tendência histórica de tais atividades anexas e periféricas, além da baixa remuneração, é serem também atingidas por novos processos de automação, o que levará a novas substituições do trabalho humano por máquinas. Não se chegará, ao menos no modo de produção capitalista, a esta substituição em absoluto, mesmo no longo prazo. Mas o intuito, sem dúvida, é atingir um ponto ótimo em que tais medidas possibilitem autonomizar a acumulação de capital frente aos ciclos recessivos de crise econômica, permitindo a geração de excedentes pela diminuição do tempo de trabalho socialmente necessário (pois se trata aqui de extração de mais-valia relativa), além da redução dos custos de reprodução da força de trabalho humana, por meio do controle social que o pânico do desemprego estrutural exerce sobre a classe trabalhadora. 


\section{CONSIDERAÇÕES FINAIS}

A expansão mundial dos produtos da Toyota na década de 80 , adentrando com força até mesmo o mercado estadunidense (RACHID, 1994), demonstrou o vigor deste sistema de organização, especialmente em vista dos ganhos de produtividade, flexibilidade e qualidade, resultantes das atividades de trabalho sob os seus moldes. Paralelamente, a automação microeletrônica rumou ao interior dos processos de trabalho, unindose à informática. Todas estas frentes de inovação expandiram-se, então, mundialmente, numa série de ensaios em quase todos os setores econômicos. ${ }^{9}$

No entanto, como os diversos estudos por nós consultados e citados neste texto demonstram, uma das conseqüências da expansão destas inovações tecnológico-organizacionais é o aumento na produtividade do trabalho seguido por um desemprego estrutural, atualmente em ascensão nos países capitalistas centrais, mas atingindo níveis altíssimos nas economias periféricas como o Brasil, o que traz à tona o caráter caótico, não exatamente do desenvolvimento científico e tecnológico, mas da sua aplicação submetida aos ditames da acumulação de capital, onde, na base do aumento da riqueza material da sociedade, está a miséria do homem que vive do trabalho.

Junto ao desemprego, novos conhecimentos são exigidos aos trabalhadores que permanecem empregados, visando garantir o desempenho das custosas máquinas que operam, o que, num contexto de desemprego estrutural elevado, como o do Brasil a partir dos anos 90, acaba necessariamente levando-os a buscar contornar, na maior parte das vezes individualmente, a desvalorização de sua força de trabalho mediante uma contínua demanda sobre os sistemas educacionais (LEITE, 1995; OLIVEIRA, 1996).

Partindo da definição de qualificação do trabalho do início deste artigo, pode-se dizer que a escola pública não apenas foi concebida, como vem se tornando cada vez mais parte do processo de estruturação da sociedade capitalista, ou seja, "como uma instituição socializadora capaz de repassar às futuras gerações o 'habitus' de seus antecessores" (OLIVEIRA, 1996, p. 58), o que fez que, desde sua origem até os dias 
atuais, tal instituição passasse por processos que refletem as diferentes transformações pelas quais esta sociedade passou.

No que tange ao conteúdo da formação educacional que fornece, se durante a vigência do taylorismo/fordismo as instituições de ensino públicas voltavam-se a uma formação mais especializada, ou à consolidação de um conjunto de conhecimentos que preparassem os alunos para uma vida profissional mais estável, atualmente tais instituições vêm buscando ofertar um ensino mais generalista, pelo qual se espera formar não apenas os novos trabalhadores polivalentes, mas também aqueles que irão percorrer inúmeros empregos instáveis. Nas palavras de Salm (1998, p. 243):

[...] além de preparar os jovens para os novos e poucos empregos que requerem capacidade de resolver problemas, espera-se que a educação também prepare os jovens para as várias formas de desemprego, [...] nas idéias de "aprender a aprender", e "educação continuada", pois está previsto que os jovens de hoje terão que mudar de "carreira" (não apenas de emprego) várias vezes ao longo de suas vidas.

No caso do Brasil, tal processo tem levado nos anos 90 a transformações profundas nas instituições de ensino. Se a política educacional brasileira reproduziu, nos vários períodos de evolução do capitalismo no país, as desigualdades sociais, chegou-se na atualidade a um estado de crise geral da rede pública de ensino, especialmente no nível voltado à formação básica, essencial ao perfil de qualificação exigido pelas recentes inovações tecnológico-organizacionais (JACOBI, 1996).

No enfrentamento destes problemas, o Brasil tem sido palco, desde o final da década de 80 , de uma investida de órgãos de financiamento multilateral e de agências de cooperação internacional - como o Banco Mundial, o Banco Interamericano de Desenvolvimento (BID), o Banco Internacional para a Reconstrução e o Desenvolvimento (BIRD), a The United Nations Educational, Scientific and Cultural Organization (UNESCO), a The United Nations Children's Fund (UNICEF) e a Organização Internacional do Trabalho (OIT), dentre outros organismos regionais e nacionais a eles vinculados -, na busca de promover uma 
valorização da educação básica geral, formadora de uma força de trabalho mais adequada às necessidades colocadas pelas formas flexíveis da atual acumulação de capital (JACOBI, 1996).

De fato, enquanto na década de 80 as três primeiras instituições citadas aplicavam recursos no ensino profissionalizante dos países periféricos, desde o final daquela década elas passaram a investir tais recursos em programas de formação básica (OLIVEIRA, 1996). Entretanto, se há um certo consenso sobre a necessidade de reformulação do conteúdo educacional da escola pública brasileira, esses movimentos vêm refletindo muito mais a visão empresarial da escola pública, condizente com as exigências da acumulação flexível do capital.

Ver a escola pública como uma instituição permeada pelas transformações e estruturas da sociedade capitalista, não implica, contudo, em concebê-la como mera agência reprodutora de relações sociais de exploração do trabalho, ou mero aparelho ideológico do Estado. Antes de tudo, devese reconhecer esta instituição como um espaço social de convivência e de relações conflituais, tanto no seu aspecto educativo, quanto como um local de trabalho e de produção de conhecimento. Assim analisada, é possível perceber a escola não apenas como um espaço de reprodução das relações sociais, mas também de resistência a determinadas direções, resultante da correlação de forças presente na luta entre os sujeitos sociais dela participantes.

Portanto, dadas as considerações de teor crítico, que muitos estudos vêm apontando acerca do avanço da reestruturação produtiva e seus efeitos sociais, cabe aos gestores de políticas públicas voltadas ao ensino e à pesquisa, bem como aos profissionais diretamente ligados a estas áreas, dentro e fora das empresas, uma reflexão sobre os riscos que envolvem a assunção de estratégias de desenvolvimento submetidas unilateralmente aos propósitos da concorrência capitalista global.

E esta reflexão se faz ainda mais pertinente se considerarmos o destino do conhecimento fundamentado no interesse histórico da classe trabalhadora, maioria absoluta da sociedade, e que se vê ameaçada de ser definitivamente privada de atuar como sujeito não apenas no âmbito do acesso aos resultados materiais do trabalho social, mas também no âmbito da sua própria formação educacional. 


\section{NOTAS}

1 Cf. Antunes (1995), Castro (1995), Curry (1993), Coriat (1993, 1994), Gounet (1999), Fleury e Vargas (1983), Ohno (1997), Posthuma (1994) e Silva (1991).

2 Cf. Harvey (1992), Mattoso (1994), Pinto (2007a, 2006) e Quadros (1991).

3 A década de 70 iniciou um período de fortes desequilíbrios econômicos, causados tanto pelo súbito aumento de preço do petróleo no mercado internacional (1973 e 1979), quanto pelas oscilações do dólar impostas pelos EUA desde em 1978 e 1985. Como decorrência deste quadro, iniciaram-se as primeiras grandes variações nas taxas de câmbio dos países, acentuando a internacionalização e o já crescente volume de investimentos financeiros especulativos, agilizados pela microeletrônica aplicada à informação (DEDECCA, 1998; TAVARES, 1992).

4 Para explicações aprofundadas a respeito da mais-valia relativa e absoluta, consultar Marx (1998). Sobre a taxa decrescente do valor de uso das mercadorias, ver Mészáros (2002) e Antunes (1999).

5 Segundo o Dicionário crítico sobre trabalho e tecnologia: "o termo automação [...] diz respeito a todo instrumento ou objeto que funcione sem a intervenção humana, podendo ser aplicado a qualquer tipo de máquina ou artefato que opere desse modo. [...] Atualmente, com a mudança em curso da automação de base eletromecânica para a de base eletroeletrônica, passa a ser utilizado o termo automatização, que ' ... implica técnicas diversas de coleta, armazenamento, processamento e transmissão de informações’ [...], materializadas em diferentes tipos de equipamentos utilizados na produção de bens e serviços. Apesar dessas diferenciações, é comum, na literatura sobre o tema, a utilização do termo automação em referência, também, às tecnologias de base microeletrônica" (CATTANI, 1999, p. 25-26).

6 Para uma análise mais densa concernente ao taylorismo, ao fordismo e ao toyotismo, consultar os já citados estudos de Harvey (1992), Curry (1993), Posthuma (1994), Castro (1995), Coriat (1993, 1994), Silva (1991), Antunes (1995), Gounet (1999) e Ohno (1997). Fazemos aqui uma fusão das palavras "taylorista/fordista", em vista de concebermos o sistema de Ford como herdeiro direto do de Taylor. Sobre este aspecto, ver Pinto (2007a).

7 Cf. Elger e Smith (1994) e Pollert (1996).

8 Termo empregado por Karl Marx, aludindo ao "exército" de desempregados, que, nesta situação, ficariam em condições de vender sua força de trabalho por quanto lhes fosse ofertado, para sobreviver.

9 No caso do Brasil, estes movimentos foram verificados a partir do final dos anos 80 e, sobretudo, ao longo dos 90 , em especial nos setores industriais mais avançados do ramo metalúrgico, mas também nos setores químico/petroquímico, têxtil, e nos setores de de serviços. Ver a respeito: Antunes (2006).

\section{REFERÊNCIAS}

ABREU, Alice Rangel de Paiva et al. Produção flexível e relações interfirmas: a indústria de autopeças em três regiões do Brasil. In: ABREU, Alice Rangel de Paiva (Org.). Produção flexível e novas institucionalidades na América Latina. Rio de Janeiro: UFRJ, 2000.

ANTUNES, Ricardo (Org.) Riqueza e miséria do trabalho no Brasil. São Paulo: Boitempo, 2006.

ANTUNES, Ricardo. Os sentidos do trabalho: ensaio sobre a afirmação e negação do trabalho. São Paulo: Boitempo, 1999. 
ANTUNES, Ricardo. Trabalho, reestruturação produtiva e algumas repercussões no sindicalismo brasileiro. In: ANTUNES, Ricardo (Org.). Neoliberalismo, trabalho e sindicatos. 2. ed. São Paulo: Boitempo, 1998.

ANTUNES, Ricardo. Adeus ao trabalho? Ensaio sobre as metamorfoses e a centralidade do mundo do trabalho. Campinas: Cortez; UNICAMP, 1995.

ARAÚJO, Ângela M. Carneiro; CARTONI, Daniela M.; JUSTO, Carolina R. D. Mello. Reestruturação produtiva e negociação coletiva nos anos 90. Revista Brasileira de Ciências Sociais. [S.I.] Associação Nacional de Pós-graduação em Ciências Sociais (ANPOCS), v. 16, n. 45, p. 85-112, fev. 2001.

BRAVERMAN, Harry. Trabalho e capital monopolista: a degradação do trabalho no século XX. 3. ed. Tradução de Nathanael C. Caixeiro. Rio de Janeiro: LTC - Livros Técnicos e Científicos, 1987.

BRUNO, Lúcia. Educação, qualificação e desenvolvimento econômico. In: BRUNO, Lúcia (Org.). Educação e trabalho no capitalismo contemporâneo: leituras selecionadas. São Paulo: Atlas, 1996.

CASTILLO, Noela Invernizzi. Automação e qualificação do trabalho: elementos para um enfoque dialético. 1996. Dissertação (Mestrado) - Instituto de Geociências/ UNICAMP, Campinas, 1996.

CASTRO, Nadya Araújo de. Modernização e trabalho no complexo automotivo brasileiro: reestruturação industrial ou japanização de ocasião? In: CASTRO, Nadya Araújo de (Org.). A máquina e o equilibrista: inovações na indústria automobilística brasileira. Rio de Janeiro: Paz e Terra, 1995.

CATTANI, Antonio David. Trabalho e tecnologia: dicionário crítico. 2. ed. Petrópolis: Vozes; Porto Alegre; UFRGS, 1999.

CORIAT, Benjamin. Ohno e a escola japonesa de gestão da produção: um ponto de vista de conjunto. In: HIRATA, Helena Sumiko (Org.) Sobre o "modelo" japonês: automatização, novas formas de organização e de relações de trabalho. São Paulo: EDUSP, 1993.

CORIAT, Benjamin. Pensar pelo avesso: o modelo japonês de trabalho e organização. Tradução de Emerson S. da Silva. Rio de Janeiro: Revan; UFRJ, 1994. 
CURRY, James. The flexibility fetish: a review essay on flexible specialisation. Capital \& Class, n. 50, summer 1993.

DEDECCA, Cláudio Salvadori. Reestruturação produtiva e tendências de emprego. In: OLIVEIRA, Marco Antônio (Org.). Economia \& Trabalho: textos básicos. Campinas: CESIT/IE; UNICAMP, 1998.

ELGER, Tony; SMITH, Chris. Global japanization? Convergence and competition in the organization of the labour process. In: SMITH, Chris; ELGER, Tony (Edits.). Global japanization? The transnational transformation of the labour process. London, New York: Routlegde, 1994.

FLEURY, Afonso e VARGAS, Nilton. Aspectos conceituais. In: FLEURY, Afonso; VARGAS, Nilton (Coord.) Organização do trabalho: uma abordagem interdisciplinar - sete estudos sobre a realidade brasileira. São Paulo: Atlas, 1983.

FREYSSENET, Michel. Formas sociais de automatização e experiências japonesas. In: HIRATA, Helena Sumiko (Org.) Sobre o "modelo" japonês: automatização, novas formas de organização e de relações de trabalho. São Paulo: EDUSP, 1993.

GOUNET, Thomas. Fordismo e toyotismo na civilização do automóvel. São Paulo: Boitempo, 1999.

HARVEY, David. A condição pós-moderna. São Paulo: Loyola, 1992.

JACOBI, Pedro. Transformações do Estado contemporâneo e educação. In: BRUNO, Lúcia (Org.). Educação e trabalho no capitalismo contemporâneo. São Paulo: Atlas, 1996.

LEITE, Elenice. Renovação tecnológica e qualificação do trabalho. In: CASTRO, Nadya Araújo de (Org.). A máquina e o equilibrista: inovações na indústria automobilística brasileira. Rio de Janeiro: Paz e Terra, 1995.

LIMA, Eurenice de Oliveira. 0 encantamento da fábrica: toyotismo e os caminhos do envolvimento no Brasil. São Paulo: Expressão Popular, 2004.

MARX, Karl. 0 capital: crítica da economia política. 3 ed. São Paulo: Nova Cultural, 1988 (Os Economistas).

MATTOSO, Jorge E. L. O novo e inseguro mundo do trabalho nos países avançados. In: OLIVEIRA, Carlos Alonso de et al. (Org.). 0 mundo do trabalho: crise e mudança 
no final do século. São Paulo: Página Aberta; Scritta, nov. 1994. p. 521-562. (Projeto Mercado de Trabalho, Sindicatos e Contrato Coletivo, MTb/PNUD, CESIT/IE/ UNICAMP, FECAMP).

MÉSZÁROS, István. Para além do capital. São Paulo: Boitempo, 2002.

OHNO, Taiichi. 0 sistema Toyota de produção: além da produção em larga escala. Porto Alegre: Bookman, 1997.

OLIVEIRA, Dalila Andrade. A qualidade total na educação: os critérios da economia privada na gestão da escola pública. In: BRUNO, Lúcia (Org.). Educação e trabalho no capitalismo contemporâneo. São Paulo: Atlas, 1996.

PINTO, Geraldo Augusto. A organização do trabalho no século XX: taylorismo, fordismo e toyotismo. São Paulo: Expressão Popular, 2007a.

PINTO, Geraldo Augusto. A máquina automotiva em suas partes: um estudo das estratégias do capital nas autopeças em Campinas. Tese (Doutorado em Sociologia) - Instituto de Filosofia e Ciências Humanas da Universidade Estadual de Campinas, Campinas, SP, 2007b.

PINTO, Geraldo Augusto. Uma introdução à indústria automotiva no Brasil. In: ANTUNES, Ricardo (Org.) Riqueza e miséria do trabalho no Brasil. São Paulo: Boitempo, 2006.

POLLERT, A. Team work on the assembly line: contradiction and the dynamics of union resilience. In: ACKERS et al. (Edits.) The new workplace and Trade Unionism. London, New York: Routledge, 1996.

POSTHUMA, Anne Caroline. Japanese production techniques in Brazilian automobile components firms: a best practice model or basis for adaptation? In: SMITH, Chris; ELGER, Tony (Edits.). Global japanization? The transnational transformation of the labour process. London, New York: Routlegde, 1994.

QUADROS, Waldir José de. Crise do padrão de desenvolvimento no capitalismo brasileiro: breve histórico e principais características. Campinas: CESIT/IE/ UNICAMP, 1991. (Cadernos do CESIT, textos para discussão n. 6).

RACHID, Alessandra. O Brasil imita oJapão? A qualidade em empresas de autopeças. 1994. Dissertação (Mestrado) - Departamento de Política Científica e Tecnológica do Instituto de Geociências da Universidade Estadual de Campinas, Campinas, SP, 1994. 
RIQUELME, Graciela C.La Gestión de Calificaciones en un Contexto de Reestructuración Productiva Internacional. In: GITAHY, Leda (Org.). Reestructuración productiva, trabajo y educación en America Latina. Campinas: IG/UNICAMP; RED CIIDCENEP: Buenos Aires, 1994.

SALM, Cláudio. Novos requisitos educacionais do mercado de trabalho. In: OLIVEIRA, Marco Antônio (Org.) Economia \& Trabalho: textos básicos. Campinas: CESIT/IE; UNICAMP, 1998.

SHIROMA, Eneida Oto. Mudança tecnológica, qualificação e políticas de gestão: a educação da força de trabalho no modelo japonês. 1993. Tese (Doutorado) - Faculdade de Educação da Universidade Estadual de Campinas, Campinas, SP, 1993.

SILVA, Elizabeth Bortolaia. Refazendo a fábrica fordista: contrastes da indústria automobilística no Brasil e na Grã-Bretanha. São Paulo: Hucitec; FAPESP, 1991.

TAVARES, Maria da Conceição. Ajuste e reestruturação nos países centrais: a modernização conservadora. Economia e Sociedade, Campinas, SP: IE/UNICAMP, Scritta, n. 1, p. 21-57, ago. 1992. 